\title{
Long-term antibiotic therapy in patients with surgery-indicated not undergoing surgery infective endocarditis
}

Nuria Vallejo Camazon ${ }^{1,2} \odot$, Lourdes Mateu ${ }^{3}$, Germán Cediel ${ }^{1}$, Laura Escolà-Vergé ${ }^{4}$, Nuria Fernández-Hidalgo ${ }^{4}$, Mercedes Gurgui Ferrer ${ }^{5}$, Maria Teresa Perez Rodriguez ${ }^{6}$, Guillermo Cuervo ${ }^{7}$, Raquel Nuñez Aragón ${ }^{8}$, Cinta Llibre ${ }^{1}$, Nieves Sopena ${ }^{3}$, Maria Dolores Quesada ${ }^{9}$ Elisabeth Berastegui ${ }^{1}$, Albert Teis ${ }^{1}$, Jorge Lopez Ayerbe ${ }^{1}$, Gladys Juncà ${ }^{1}$, Francisco Gual ${ }^{1}$, Elena Ferrer Sistach ${ }^{1}$, Ainhoa Vivero ${ }^{8}$, Esteban Reynaga ${ }^{3}$, María Hernández Pérez ${ }^{10}$, Christian Muñoz Guijosa ${ }^{1}$, Lluisa Pedro-Botet ${ }^{2,3}$, Antoni Bayés-Genís ${ }^{1,2}$

${ }^{1}$ Heart Institute, Hospital Universitari Germans Trias i Pujol, Badalona, Barcelona, Spain; ${ }^{2}$ Department of Medicine, CIBERCV, Autonomous University of Barcelona, Barcelona, Spain; ${ }^{3}$ Unitat Malalties Infeccioses, Hospital Universitari Germans Trias i Pujol, Badalona, Barcelona, Spain; ${ }^{4}$ Servei de Malalties Infeccioses, Hospital Universitari Vall d'Hebron, Universitat Autònoma de Barcelona, Barcelona, Spain;

${ }^{5}$ Unitat de Malalties Infeccioses, Hospital Santa Creu i Sant Pau, Universitat Autonoma de Barcelona, Barcelona, Spain; ${ }^{6}$ Unidad de Enfermedades Infecciosas, Servicio de Medicina Interna, Complexo Hospitalario de Vigo, Vigo, Spain; ${ }^{7}$ Department of Infectious Diseases, Bellvitge University Hospital, L'Hospitalet de Llobregat, Barcelona, Spain; ${ }^{8}$ Internal Medicine Department, Hospital Universitari Germans Trias i Pujol, Badalona, Barcelona, Spain; ${ }^{9}$ Microbiology Department, Hospital Universitari Germans Trias i Pujol, Badalona, Barcelona, Spain; ${ }^{10}$ Neurology Department, Hospital Universitari

Germans Trias i Pujol, Badalona, Barcelona, Spain

\begin{abstract}
Background: To date, there is little information regarding management of patients with infective endocarditis (IE) that did not undergo an indicated surgery. Therefore, we aimed to evaluate prognosis of these patients treated with a long-term antibiotic treatment strategy, including oral long term suppressive antibiotic treatment in five referral centres with a multidisciplinary endocarditis team.

Methods: This retrospective, multicenter study retrieved individual patient-level data from five referral centres in Spain. Among a total of 1797, 32 consecutive patients with IE were examined (median age 72 years; $78 \%$ males) who had not undergone an indicated surgery, but received long-term antibiotic treatment (LTAT) and were followed by a multidisciplinary endocarditis team, between 2011 and 2019. Primary outcomes were infection relapse and mortality during follow-up.

Results: Among 32 patients, 21 had IE associated with prostheses. Of the latter, 8 had an ascending aorta prosthetic graft. In 24 patients, a switch to long-term oral suppressive antibiotic treatment (LOSAT) was considered. The median duration of LOSAT was 277 days. Four patients experienced a relapse during follow-up. One patient died within 60 days, and 12 patients died between 60 days and 3 years. However, only 4 deaths were related to IE.

Conclusions: The present study results suggest that a LTAT strategy, including LOSAT, might be considered for patients with IE that cannot undergo an indicated surgery. After hospitalization, they should be followed by a multidisciplinary endocarditis team. (Cardiol J 2021; 28, 4: 566-578)
\end{abstract}

Key words: suppressive antibiotic treatment, infective endocarditis, surgery

Address for correspondence: Nuria Vallejo Camazon, MD, Heart Institute, Hospital Universitari Germans Trias I Pujol, Carretera de Canyet s/n 08916, Badalona (Barcelona) Spain, tel: 934978915/934978863, e-mail: nvallejo73@hotmail.com

This article is available in open access under Creative Common Attribution-Non-Commercial-No Derivatives 4.0 International (CC BY-NC-ND 4.0) license, allowing to download articles and share them with others as long as they credit the authors and the publisher, but without permission to change them in any way or use them commercially. 


\section{Introduction}

Infective endocarditis (IE) is a severe, complex entity with high morbidity, inhospital mortality (20-30\%) [1], and long-term mortality ( $45 \%)$ [2], despite recent advances in diagnostic and therapeutic strategies [3-5]. The epidemiology of IE has changed [6-8] towards patients with multiple comorbidities, prostheses, devices, congenital heart diseases, or transcatheter procedures [9].

Cardiac surgery and antibiotic treatment are the cornerstones of IE treatment. According to current recommendations [10], more than $70 \%$ of patients with IE have an indication for surgery, but less than 50\% finally undergo operations, due to surgical risk [11-13]. In-hospital mortality is high $(\sim 70 \%)$ among patients with surgery indicated not undergoing surgery IE (SINUS-IE). However, information is sparse regarding the clinical characteristics and long-term outcomes for these patients [14].

Clinical guidelines [10] do not specifically mention antibiotic treatment or a recommended treatment duration for patients with SINUS-IE. Oral antibiotics have shown to be effective for shortening intravenous treatment in selected cases of uncomplicated left-sided IE [15]; however, there is a lack information regarding oral long-term antibiotic treatment (LTAT) in the context of SINUS-IE. Moreover, new imaging techniques [16], such as positron emission tomography/computed tomography (PET/CT) might play a role in monitoring responses and establishing an appropriate duration for LTAT $[17,18]$ in SINUS-IE.

We hypothesized that an approach managed by a multidisciplinary endocarditis team (MDET) that included individualized LTAT, long-term oral suppressive antibiotic treatment (LOSAT) when needed, and close follow-up might improve the long-term prognosis in SINUS-IE. Accordingly, this study aimed to evaluate the clinical characteristics and outcome of patients with SINUS-IE treated with long-term antibiotic regimens in 5 Spanish referral centres.

\section{Methods}

\section{Study design and data collection}

For this multicenter, retrospective, observational study, patient-level data was collected from local, prospective databases at 5 hospitals in Spain from January 2011 to January 2019. The 5 hospitals were referral centres for IE with cardiac surgery facilities. In addition, MDETs held regular meet- ings to discuss and evaluate therapeutic strategies for patients with IE.

We included adult patients (age $\geq 18$ years) with a definite diagnosis of IE (based on modified Duke criteria/European Society of Cardiology (ESC) criteria, modified in August 2015) and an indication for surgery or device extraction, according to clinical guidelines [10]. None of these patients underwent surgical procedures after an evaluation by the MDET. All these patients survived the index hospitalization with a plan established by the local MDET for long-term intravenous treatment ( $>8$ weeks) or LOSAT. Patients with fungal IE were excluded. For patients with relapses, only the episode in which the local committee decided to treat with LTAT was included. Patients that had been discharged with a plan for LTAT during follow-up were also included.

Data were obtained on demographics, clinical parameters, diagnostics (imaging, microbiological, and analytical parameters), and follow-up. A simplified, standard case-report form was designed. Data were recorded anonymously and sent to the coordinating institution, where a database was created specifically for this study.

\section{Definitions}

Healthcare-associated endocarditis was defined elsewhere [19].

The Charlson comorbidity index [20] (not age adjusted) was used at admission to stratify overall co-morbidity.

Moderate or severe renal disease was defined as an estimated glomerular filtration rate (based on CKD-EPI method) below $60 \mathrm{~mL} / \mathrm{min} / 1.73 \mathrm{~m}^{2}$ at admission.

Surgery was defined as the replacement or repair of the affected heart valve during the index hospitalization.

Indications for surgery were adjudicated prospectively during the index episode by the local MDET, and they included: heart failure, embolic event prevention, and uncontrolled infection [10]. The EuroSCORE [21, 22] (logistic EuroSCORE I and EuroSCORE II) was calculated for all patients. For IEs related to a cardiovascular implantable electronic device (CIED), percutaneous device extraction was considered an indication for surgery.

Follow-up was defined as the period from the day antibiotic treatment for IE was started until death for any reason or the last follow-up. Data was collected at the end of intravenous antibiotic treatment, the beginning of oral antibiotic treatment, when administered, and at the end of an oral antibiotic prescription, after completion. 
After discharge for IE, survivors were prospectively followed at regular intervals. Each local MDET established the periodicity of blood cultures, clinical evaluations, and imaging (PET/CT and/or echocardiograms).

Long-term antibiotic treatment (LTAT) was defined as an intravenous or oral antibiotic regimen that exceeded the standard duration (usually $<8$ weeks) of the established treatment for an episode of native, device-related, or prostheticrelated IE. When patients were switched to oral treatment, the term long-term oral suppressive antibiotic treatment (LOSAT) was used. The MDET determined, a priori, whether the duration of this treatment was time-defined or life-long. However, the treatment durations were re-evaluated at follow-ups. Durations were based on patient status evolution and the response to treatment, according to analytical, clinical, and cardiac imaging parameters. When intravenous treatment was required, an outpatient parenteral antibiotic therapy regimen was preferred.

Relapse was defined as a documented, positive blood culture, caused by the same microorganism that caused the initial IE, and being observed within the first year after completing the standard established antimicrobial treatment.

Mortality was defined as death from any cause during follow-up. The causes of IE-related mortality were: heart failure, stroke, uncontrolled infection, sudden death, and other causes attributable to any IE complication.

\section{Outcomes}

Primary outcomes were: infection relapse and mortality at the last follow-up.

\section{Ethics}

This study was performed in compliance with the Helsinki Declaration and was approved by the local Ethics Committee of Hospital Universitari Germans Trias i Pujol (Badalona, Barcelona, Spain).

\section{Statistical analysis}

Categorical variables are expressed as absolute numbers and percentages. Continuous variables are expressed as the mean and standard deviation (SD) or the median and 25-75 percentile (interquartile range [IQR]), according to the data distribution (normal or non-normal). Survival was evaluated with the Kaplan-Meier method and long-rank test. All analyses were performed with STATA V.13.0 (College Station, Texas, United States).

\section{Results}

\section{Baseline characteristics}

Between January 2011 and January 2019, 1797 patients with IE were identified in 5 participating centres. Among these, we identified 32 discharged patients with SINUS-IE managed with a LTAT strategy. The median follow-up time from diagnosis was 487 days (IQR: $332-1210$ days). The baseline patient characteristics are detailed in Table 1 . The mean age was $72.1 \pm 17$ years and $78 \%$ were males. Twenty-one (66\%) patients had prosthetic valve endocarditis (PVE). Of these, 20 were left-sided and one was right-sided PVE. Eight patients suffered PVE before 1 year from valvular surgery (early PVE) and the other 13 corresponded to late PVE. Seven patients had CIED-related IE (Table 2). In these cases, the device was either not extracted or incompletely extracted, which were counterindications for surgery. Four patients had left-sided native valve IE; $17(53 \%)$ had healthcare-associated IE, and $14(43.7 \%)$ had a history of previous IE. Of note, $8(25 \%)$ patients had ascending aorta prosthetic grafts (AAGs; Table 3).

Most patients had comorbidities. The mean Charlson index was 5 points (range: $3-7$ ). The main indication for surgery was uncontrolled infection (75\%), and 18 patients had local complications. The main reasons for not undergoing surgery, despite the indication, were: high surgical risk (75\%), surgeon refusal, due to an unaffordable technical risk $(15.6 \%)$, and patient refusal $(6.2 \%)$.

\section{Analysis of microbiological data, imaging data, treatment, and outcomes}

Twenty-four $(75 \%)$ patients underwent transesophageal echocardiography (TEE) and 20 (63\%) patients underwent a PET/CT. Remarkably, in 7 patients ( 5 with AAGs), the PET/CT established the IE diagnosis after a previous negative or inconclusive TEE.

Blood cultures were positive in $94 \%$ of patients. The most prevalent microorganisms were coagulase-negative staphylococci $(10 / 32,31 \%)$ and Staphylococcus aureus (7/32, 22\%). Blood cultures were negative in 2 patients that had previously received antibiotic treatment. Of these, one had previous cardiac surgery, and the surgery wound culture was positive for S. epidermidis; the other had undergone surgery 2 months prior for native aortic valve IE associated with $S$. sanguis; thus, this patient was treated for a relapse/early PVE.

The median duration of parenteral antibiotic treatment was 8 weeks (IQR: 6-12 weeks). In 
Table 1. Baseline demographic, clinical, and microbiological characteristics of the study subjects.

\begin{tabular}{|c|c|}
\hline Parameters & $\begin{array}{c}\text { Overall } \\
(n=32)\end{array}$ \\
\hline Age [years] & $72 \pm 17$ \\
\hline Male sex & $25(78.1)$ \\
\hline Healthcare-associated IE & $17(53.1)$ \\
\hline \multicolumn{2}{|l|}{ Type of infection } \\
\hline Prosthetic valve IE & $21(65.6)$ \\
\hline Early/late PVE & $8 / 13$ \\
\hline Intracardiac device-related IE & $7(21.9)$ \\
\hline Native IE & $4(12.5)$ \\
\hline \multicolumn{2}{|l|}{ Clinical history-comorbidities } \\
\hline Previous cardiac surgery & $19(59.4)$ \\
\hline Previous IE & $14(43.8)$ \\
\hline Chronic renal failure & $14(43.8)$ \\
\hline Hemodyalisis & $3(9.4)$ \\
\hline Diabetes mellitus & $9(28.1)$ \\
\hline COPD & $5(15.6)$ \\
\hline Severe liver disease & $4(12.5)$ \\
\hline Cancer & $4(12.5)$ \\
\hline HIV & $1(3.1)$ \\
\hline $\begin{array}{l}\text { Charlson comordity index, } \\
\text { median (IQR) }\end{array}$ & $5(3-7)$ \\
\hline \multicolumn{2}{|l|}{ Laboratory tests } \\
\hline Hemoglobin [g/dL] & $10.2 \pm 2.02$ \\
\hline CRP [mg/L], median (IQR) & $33(12-124)$ \\
\hline eGFR $\left[\mathrm{mL} / \mathrm{min} / 1.73 \mathrm{~m}^{2}\right]$ & $52.9 \pm 24$ \\
\hline \multicolumn{2}{|l|}{ Echocardiography-PET/CT } \\
\hline TEE performed & $24(75)$ \\
\hline PET/CT performed & $20(62.5)$ \\
\hline Control PET/CT performed & $12(37.5)$ \\
\hline Local complication & $18(56.3)$ \\
\hline Vegetation present & $12(37.5)$ \\
\hline $\begin{array}{l}\text { Moderate or severe valve } \\
\text { regurgitation }\end{array}$ & $8(25)$ \\
\hline \multicolumn{2}{|l|}{ Microbiology } \\
\hline Coagulase-negative staphylococci & $10(31.3)$ \\
\hline Staphylococcus aureus & $7(21.9)$ \\
\hline Streptococcus spp & $4(12.5)$ \\
\hline Enterococcus faecalis & $4(12.5)$ \\
\hline Non-HACEK Gram-negative bacili & $2(6.3)$ \\
\hline Negative blood cultures & $2(6.3)$ \\
\hline Others & $3(9.4)$ \\
\hline \multicolumn{2}{|l|}{ Complications } \\
\hline Embolization & $8(25)$ \\
\hline Stroke & $6(18.8)$ \\
\hline Heart failure & $5(15.6)$ \\
\hline
\end{tabular}

Table 1 (cont.). Baseline demographic, clinical, and microbiological characteristics of the study subjects.

\begin{tabular}{lc}
\hline Parameters & $\begin{array}{c}\text { Overall } \\
\text { (n = 32) }\end{array}$ \\
\hline $\begin{array}{l}\text { Atrioventricular block } \\
\text { Shock }\end{array}$ & $3(9.4)$ \\
Indication for surgery & $1(3.1)$ \\
Hemodynamic & \\
Uncontrolled infection & $1(3.1)$ \\
$\quad$ Local complication & $24(75)$ \\
Embolic & 18 \\
Device infection & $1(3.1)$ \\
EuroSCORE I (\%), median (IQR) & $6(18.8)$ \\
EuroSCORE II (\%), median (IQR) & $32(17-46)$ \\
Reasons for no surgery & $9.1(6.7-14)$ \\
Unaffordable surgical risk & \\
Patient refusal & $24(75)$ \\
Intra-surgery clinical complication* & $2(6.3)$ \\
Surgeon refusal (technical risk) & $1(3.1)$ \\
Outcome & $5(15.6)$ \\
0 to 60-day mortality & \\
Cumulative 3-year mortality & $1(3.1)$ \\
Related to IE & $12(37)$ \\
Relapses & $4(12.5)$ \\
\hline & $4(12.5)$ \\
\hline a & \\
\hline
\end{tabular}

Data are presented as the number $(\%)$ and mean \pm 1 standard deviation, unless otherwise indicated. *Neurological complication during surgery without valve surgery attempted. COPD — chronic obstructive pulmonary disease; CRP - C-reactive protein; eGFR - estimated glomerular filtration rate; HIV - human immunodeficiency virus; IE — infective endocarditis; IQR — interquartile range; $\mathrm{PET} / \mathrm{CT}$ - positron emission tomography/computed tomography; PVE - prosthetic valve endocarditis; TEE - transesophageal echocardiography

8 cases, only parenteral LTAT was administered, based on a decision by the local MDET. This treatment lasted 34 weeks (range: $8-34$ ) and was administered in an outpatient or day care setting (Table 4).

Twenty-four (75\%) patients were switched to LOSAT after prolonged (12 patients) or adjusted to guidelines (12 patients) parenteral administration. In 23 patients, the MDET initially established LOSAT as a life-long treatment, starting at discharge. The median duration of LOSAT was 277 days (IQR: 73-868).

Nine patients underwent PET/CTs to guide the duration and response to treatment. In these patients, the LOSAT was stopped, based on PET/ /CT information. None of these patients experienced infection relapse. 
Table 2. Description of seven episodes of device infective endocarditis treated with oral long suppressive antibiotic treatment.

\begin{tabular}{|c|c|c|c|c|c|c|}
\hline $\begin{array}{l}\text { Age } \\
\text { [years] }\end{array}$ & Sex & $\begin{array}{l}\text { Underlying } \\
\text { condition }\end{array}$ & Etiology & $\begin{array}{l}\text { Percutaneous } \\
\text { extraction } \\
\text { tried }\end{array}$ & $\begin{array}{l}\text { Antibiotic } \\
\text { treatment } \\
\text { and duration }\end{array}$ & $\begin{array}{c}\text { Final status } \\
\text { (follow-up, } \\
\text { years) }\end{array}$ \\
\hline 87 & Male & CRF, diabetes & S. epidermidis & Yes & $\begin{array}{l}\text { CMX 160/800 mg bid } \\
\text { Longlife }\end{array}$ & $\begin{array}{c}\text { Relapse (0.2) } \\
\text { Alive (3.2) }\end{array}$ \\
\hline 89 & Male & CRF & S. aureus & No & $\begin{array}{l}\text { CMX 160/800 mg bid } \\
\text { Longlife }\end{array}$ & $\begin{array}{l}\text { Death }(0.8) \\
\text { Not related }\end{array}$ \\
\hline 91 & Male & CRF & S. aureus & No & $\begin{array}{c}\text { CMX 160/800 mg bid } \\
\downarrow \\
\text { LVF } 500 \mathrm{mg} \text { OD } \\
\text { Longlife }\end{array}$ & Alive (1.6) \\
\hline 88 & Female & Diabetes & S. aureus & Yes & $\begin{array}{c}\text { LVF } 500 \mathrm{mg} / 2 \text { days } \\
\text { Longlife }\end{array}$ & Alive (6.6) \\
\hline 82 & Male & CRF, COPD & S. epidermidis & No & $\begin{array}{c}\text { LVF } 250 \mathrm{mg} / 2 \text { days } \\
\text { (+ Rifampicine } 300 \mathrm{mg} \\
\text { OD } 4 \text { months) }\end{array}$ & $\begin{array}{l}\text { Death (3.5) } \\
\text { Not related }\end{array}$ \\
\hline 93 & Female & CRF, hepatopathy & $\begin{array}{c}\text { Enterococcus } \\
\text { faecalis }\end{array}$ & No & $\begin{array}{l}\text { Amoxicilin } 1 \mathrm{~g} \text { TD } \\
\text { Longlife }\end{array}$ & $\begin{array}{l}\text { Death }(0.4) \\
\text { Not related }\end{array}$ \\
\hline 69 & Male & COPD, hepatopathy & S. epidermidis & Yes & $\begin{array}{c}\text { Amoxicilin } 1 \mathrm{~g} \text { TD } \\
\text { Longlife }\end{array}$ & Alive (0.8) \\
\hline
\end{tabular}

CMX - cotrimoxazole; COPD — chronic obstructive pulmonary disease; CRF — chronic renal failure; LVF — levofloxacine; bid - bis in die (twice a day); QD - quaque die (once a day); TD — ter in die (three times a day)

Long-term oral suppressive antibiotic treatment comprised a variety of oral antimicrobial classes. In initial treatments, 9 patients received beta-lactams, 9 patients received trimethoprimsulfamethoxazole (TMP/SMX), 2 patients received clindamycin, and 4 patients received fluoroquinolones (levofloxacin). Others agents were combined with the initial treatment or were used during follow-up, including linezolid $(\mathrm{n}=2)$ and rifampicin (combined with levofloxacin, $\mathrm{n}=1$ ). Four $(17 \%)$ patients experienced adverse drug-related events, including thrombocytopenia $(\mathrm{n}=2)$, associated with linezolid, and digestive intolerance $(n=1)$ and a skin disorder $(n=1)$, associated with TMP/SMX. Only 1 of these patients required definitive LOSAT discontinuation. In 2 cases, in vitro resistance was resolved with another antibiotic treatment option. Some antibiotic regimens and doses are described in Tables 2 and 3.

Four patients experienced infection relapses during follow-up. All had positive blood cultures, but no clinical repercussion. The median time to relapse was 144 days (IQR: 72-210). The first relapse was a late PVE associated with Streptococcus viridans. An aortic abscess was treated with oral amoxicillin ( $3 \mathrm{~g} /$ day), which was stopped after 1 year, due to clinical stability; subsequently, positive blood cultures were documented. Life-long amoxicillin was re-started, and the patient is currently doing well in follow-up. The second relapse was a CIED-related IE, associated with coagulase-negative Staphylococcus and incomplete extraction of the CIED lead. The patient was switched to oral TMP/ /SMX. After 2 months, positive blood cultures were detected, but without clinical repercussion, and the same antibiotic regimen that was used in the follow-up. The third relapse was a prosthetic valve (Bentall surgery) IE, associated with coagulase-negative Staphylococcus. The patient was treated with TMP/SMX LOSAT, but after 5 months, the patient developed in vitro resistance to TMP/SMX. After switching to oral clindamycin, the IE showed a favourable evolution. The fourth relapse was an early PVE, associated with coagulase-negative Staphylococcus. The patient was switched to oral linezolid (600 mg bid). After 3 months, during treatment, positive blood cultures were detected, and the treatment was switched to intravenous vancomycin for 4 weeks. Subsequently, the patient was treated with oral TMP/SMX (160/800 mg bid), which was stopped after 1 year, due to stable infection and clinical stability and disease improvement, based on PET/CT.

The estimated overall survival rates were $78 \%$ at 1 year and $62 \%$ at 3 years (Fig. 1). Only 1 patient died within 60 days, due to an uncontrolled infection during treatment. Twelve patients died between 60 days and 3 years, but only 4 deaths 


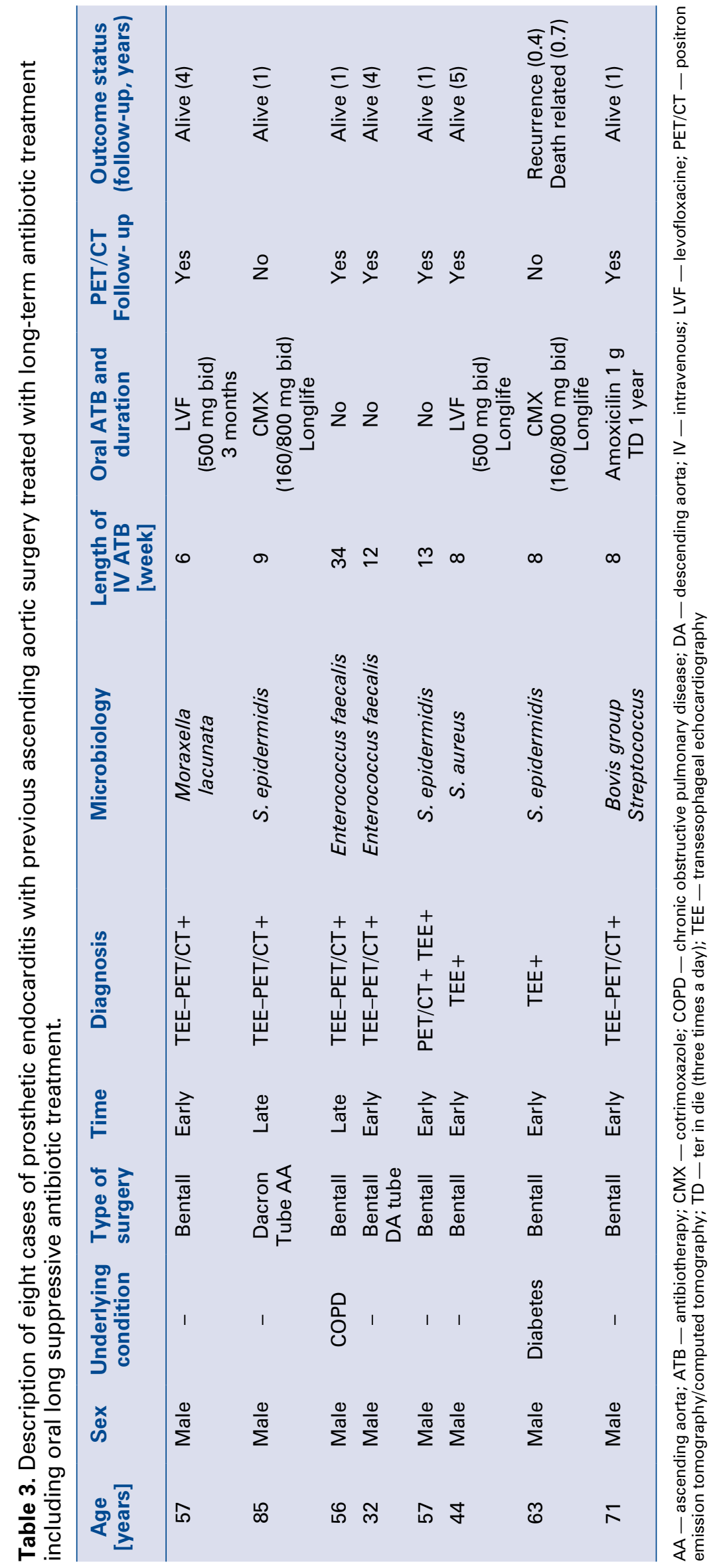




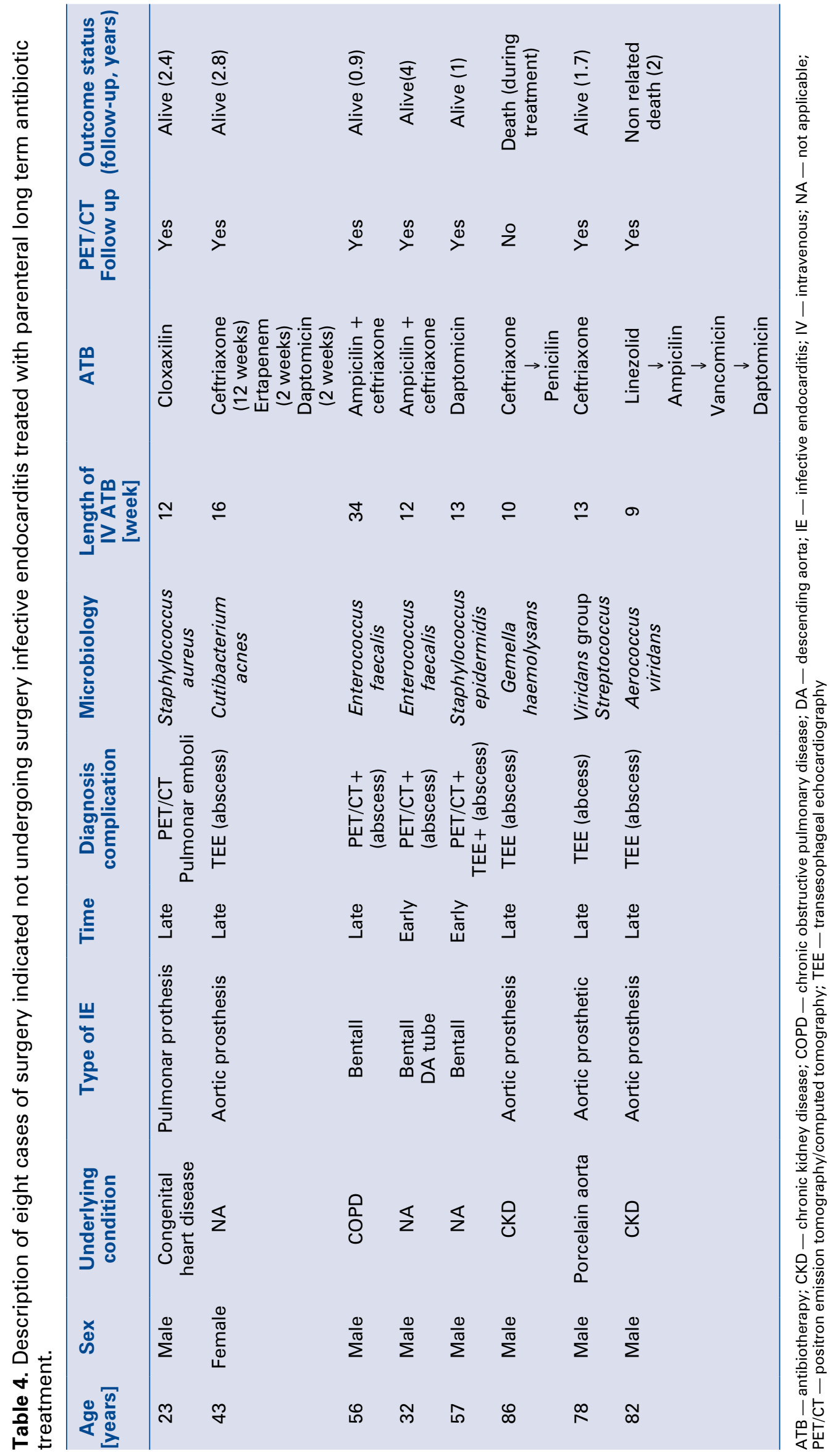




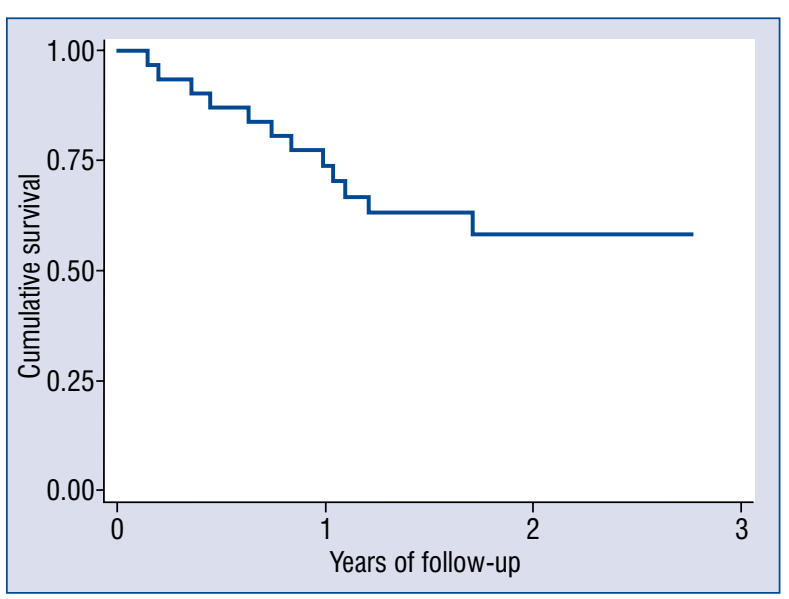

Figure 1. Survival in surgery indicated, but did not undergo surgery for infective endocarditis patients treated with long term antibiotic treatment.

were related to IE (due to uncontrolled infection in 1 patient, stroke in 2 patients, and heart failure in 1 patient). After 3 years of follow-up, 3 more deaths occurred that were unrelated to IE. Of note, in the group with SINUS-IE that had AAGs, only 1 IE-related death occurred after a previous relapse (Table 3), and in the CIED device IE group, 3 deaths occurred that were unrelated to IE (Table 2).

\section{Discussion}

According to available research, this study included the largest series (including left sided IE) to date in describing the experiences and outcomes of patients with SINUS-IE treated with LTAT, including those that switched to LOSAT. All previous studies were small, retrospective studies or case reports (Table 5). An overall survival of $62 \%$ at 3 years, and only 4 relapses were observed.

Successful IE treatment requires prolonged bactericidal antibiotic treatment and surgery to remove infected material and drain abscesses. Current indications for surgery in IE are well defined in the American Heart Association and ESC guidelines [10,23]. They include valve dysfunction that leads to heart failure, uncontrolled infection (defined as a paravalvular extension, abscess, or persistent bacteremia), and recurrent/high risk of embolism. More than $50 \%$ of patients with IE meet the surgical criteria, according to clinical guidelines [24], but of those, 20-40\% do not undergo surgery due to high perioperative risk $[11,14,25]$. In-hospital mortality is high in SINUS-IE, typically due to shock and heart failure; only one third of patients survive past the index hospitalization [14]. In the present study, among the patients with SINUS IE that were treated with LTAT and survived the acute phase of IE, the main indication for surgery was uncontrolled infection (75\% of patients), including $18(56 \%)$ patients with local complications (mainly perianular abscesses) detected in imaging.

Guideline recommendations concerning antibiotic treatments and durations are not sufficiently evidence-based for SINUS-IE, due to the lack of randomized controlled trials [9]. The standard treatment for IE is 2-6 weeks of intravenous antibiotic treatment. This treatment is suitable for classical, uncomplicated, prosthetic-, native-, or device-related IE, but clinical guidelines do not mention antibiotic treatment or durations for patients with SINUS-IE. Consequently, patients with SINUS-IE are treated according to local experience, in a heterogeneous manner.

In the present study, 7 patients with local complications received prolonged LTAT. A recent study described treating IE with dalbavancin [26], a long-acting lipoglycopeptide antibiotic with excellent anti-staphylococcal activity and a half-life of $346 \mathrm{~h}$. This treatment might be an attractive option for staphylococcal-associated endocarditis, in patients with SINUS-IE that cannot tolerate oral antibiotic treatment. A recent case study showed a favourable outcome with dalvabancin [27]. In the present study, due to the retrospective design, no patients were treated with dalvabancin.

The role of oral antibiotic therapy in treating IE remains controversial [28]. Oral antibiotics have high bioavailability and have been effective in shortening intravenous treatment and treating selected cases of uncomplicated IE caused by susceptible organisms [15, 28-31]. Recently, an intervention study [32] demonstrated that a rapid switch to oral TMP/SMX reduced the hospital stay and mortality in S. aureus-associated IE, including patients with cardiac abscesses or persistent bacteremia. Oral LOSAT for patients with SINUS-IE has only been described in case reports [33], in case series for some specific situations (e.g., fungal IE [34], CIED--related IE [35, 36], aortic grafts [37]), and briefly, in some contemporary series [25] and reviews [9].

Prosthetic graft infection is a fatal complication after thoracic aorta replacement; early mortality was reported to be $25-42 \%$ [38]. In the present study, 8 patients with SINUS-IE that developed PVE after a previous surgery involving the aortic root and ascending aorta (Bentall procedure or ascending aorta graft replacement) were treated 


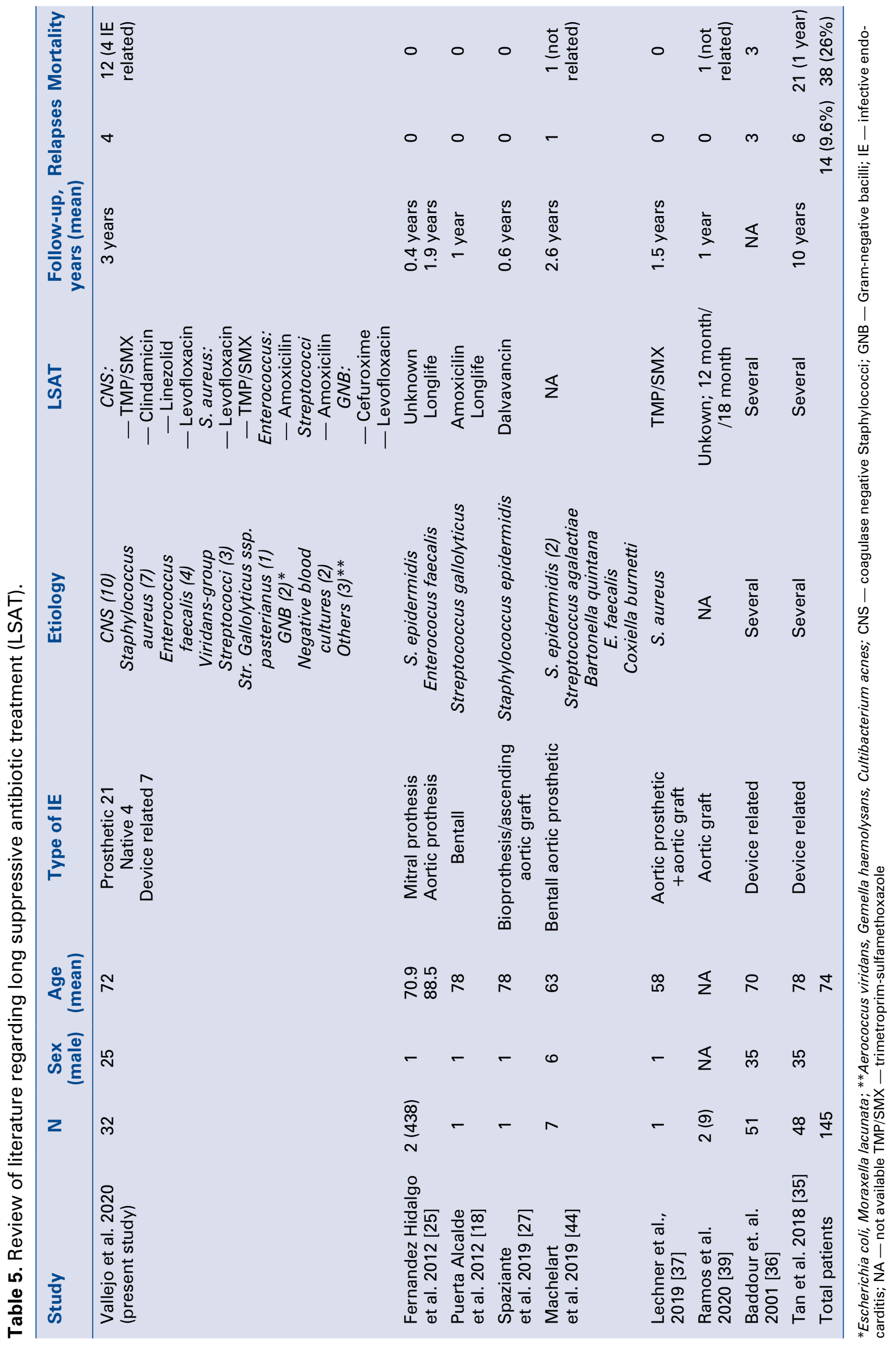


with LTAT. Five of these patients were treated orally (two life-long treatments), and only one death occurred during follow-up. The diagnosis and management of PVE after aortic root or ascending aorta graft surgery are difficult and require long-term, combined antibiotic treatment and surgery, when possible [39]. In patients with inconclusive echocardiographic results, a combination of PET/ /CT and cardiac CT is recommended [40, 41] (among our 8 patients, 5 were diagnosed with $\mathrm{PET} / \mathrm{CT}$ after inconclusive or negative TEEs). Consistent with some previous reports [37, 42-44], the present findings suggested that individualized LTAT might be effective (when there is no valvular dysfunction) in select patients with PVE complicated with AAG infections that are unfit to undergo surgery. Another option could be conservative surgery with valvular replacement and AAG preservation. However, the risk of recurrence is high; thus, chronic antibiotic suppressive treatment has been recommended, in some cases [38].

Positron emission tomography/computed tomography is a functional molecular imaging technique that depicts metabolic activity. Several studies $[16,17,41]$ have shown its utility for diagnosing PVE. Recently, ESC IE guidelines [10] have included abnormal activity around a prosthetic valve as a major criterion and embolic phenomena as a minor criterion for diagnosing PVE. In the present study, PET/CT was performed as a diagnostic tool in $62.5 \%$ of patients. Additionally, PET/CT has shown promise in monitoring responses to antimicrobial treatment in PVE, as suggested in small observational studies [18]. On the other hand, sometimes, false-negative findings have been attributed to low inflammatory activity at the time of imaging, caused by prolonged antibiotic therapy. In the present study, PET/CT was used to guide the cessation of LOSAT in 9 patients. Those patients had favourable outcomes, after antibiotic treatment was stopped, due to a reduction or termination of metabolic uptake detected with PET/CT. More large-scale studies are warranted to investigate this indication.

In the present study, 7 patients with CIED-related IE were treated with LOSAT. Of these, 3 patients had incomplete percutaneous extractions, and the other 4 had comorbidities that counterindicated percutaneous extraction, as judged by the MDET. Of these 7 patients, only one experienced a relapse, and no IE-related deaths occurred. LOSAT was also given to select patients with device-related IE that were ineligible for device removal (either surgical or percutaneous) or patients that experienced incomplete removal [45]. Currently, no comparable studies on LOSAT are available. Therefore, the optimal choice, dose, or duration of antibiotic treatment remain undefined; different outcomes have been reported in the few small observational studies that were published [35, 36].

The 5 hospitals included in the present study had a MDET that was comprised of cardiac imaging experts, cardiac surgeons, microbiologists, and infectious disease specialists. Previous studies showed that a team-based approach reduced the 1-year mortality in a mixed cohort of medically and surgically managed patients with IE [46, 47]. Additionally, a recent study [48] showed improved survival in patients that were managed medically. The present study showed that close follow-up and individualized treatment, supported with cardiac imaging, could improve the long-term prognosis in patients with SINUS-IE treated with LTSAT including LOSAT. Based on our experience, we propose an algorithm (Fig. 2) for guiding the management of patients with SINUS-IE and treatment with LOSAT.

\section{Limitations of the study}

This study had several limitations. First, antibiotic treatment was heterogeneous, because administration was at the discretion of the physician and the center, according to local protocols. Second, the definition of LOSAT was established ad hoc. Third, patient-level data were retrospective, pooled, and prospectively analyzed. Proposed algorithm is based on our own local experience without previous supporting clinical evidence.

\section{Conclusions}

Surgery indicated not undergoing surgery IE remains a dreadful complication, and we lack evidence-driven management guidelines. Herein, it was shown that survivors could achieve a reasonable long-term prognosis with an MDET-based, managed approach, with close follow-up, individualized antibiotic treatment, including LOSAT, and guidance from new imaging techniques. More multicenter prospective studies are needed to validate the proposed algorithm and to establish an appropriate long-term strategy for treating patients with SINUS-IE.

\section{Funding}

Antoni Bayes-Genis was supported by grants from the Ministerio de Educación y Ciencia (SAF2014-59892), Fundació La MARATÓ de TV3 (201502, 201516), CIBER Cardiovascular 


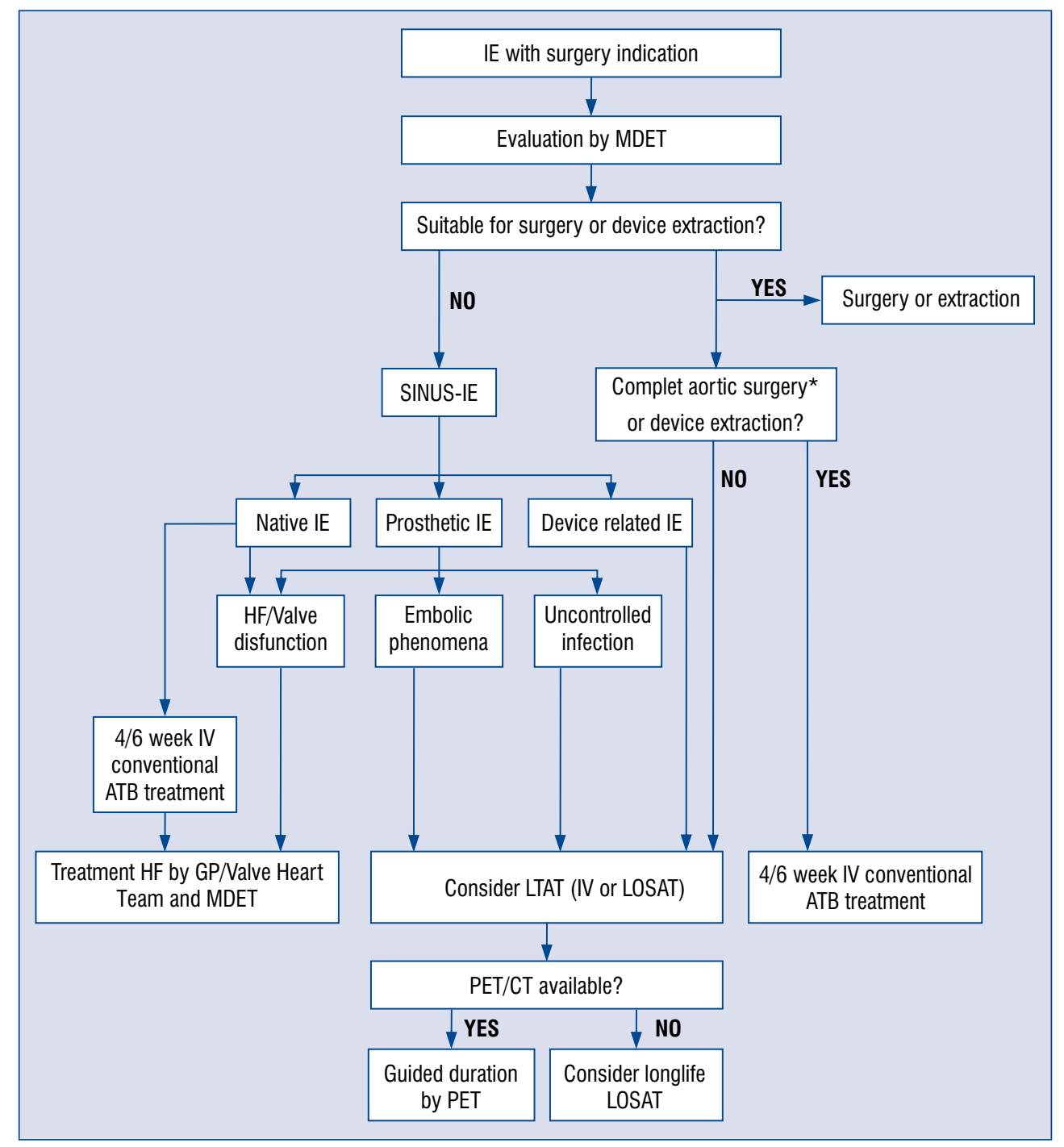

Figure 2. Proposed algorithm for treating surgery indicated, but did not undergo surgery for infective endocarditis (SINUS-IE) with long term antibiotic treatment (LTAT); MDET — multidisciplinary endocarditis team; IE — infective endocarditis; IV — intravenous; HF — heart failure; GP — general practitioner; LOSAT — long-term oral suppressive antibiotic treatment; PET/CT — positron emission tomography/computed tomography; ATB — antibiotherapy; *In cases of ascending aortic graft preservation.

(CB16/11/00403), and AdvanceCat 2014. María Hernández Pérez is supported by a Juan Rodes research contract (JR17/00006) from Instituto de Salud Carlos III.

\section{Conflict of interest: None declared}

\section{References}

1. Hoen B, Duval X. Infective endocarditis. N Engl J Med. 2013; 368(15): 1425-1433, doi: 10.1056/nejmcp1206782.

2. Østergaard L, Oestergaard LB, Lauridsen TK, et al. Long-term causes of death in patients with infective endocarditis who undergo medical therapy only or surgical treatment: a nationwide population-based study. Eur J Cardiothorac Surg. 2018; 54(5): 860-866, doi: 10.1093/ejcts/ezy156, indexed in Pubmed: 29648662.

3. Thuny F, Grisoli D, Collart F, et al. Management of infective endocarditis: challenges and perspectives. Lancet. 2012; 379(9819): 965-975, doi: 10.1016/S0140-6736(11)60755-1, indexed in Pubmed: 22317840.

4. Cahill TJ, Baddour LM, Habib G, et al. Challenges in Infective Endocarditis. J Am Coll Cardiol. 2017; 69(3): 325-344, doi: 10.1016/j.jacc.2016.10.066, indexed in Pubmed: 28104075.

5. San Román JA, Vilacosta I, López J, et al. Critical questions about left-sided infective endocarditis. J Am Coll Cardiol. 2015; 66(9): 1068-1076, doi: 10.1016/j.jacc.2015.07.016, indexed in Pubmed: 26314535.

6. Olmos C, Vilacosta I, Fernández-Pérez C, et al. The evolving nature of infective endocarditis in spain: a population-based study 
(2003 to 2014). J Am Coll Cardiol. 2017; 70(22): 2795-2804, doi: 10.1016/j.jacc.2017.10.005, indexed in Pubmed: 29191329.

7. Delahaye F, Duclos A. Is infective endocarditis changing over time? J Am Coll Cardiol. 2017; 70(22): 2805-2807, doi: 10.1016/j.jacc.2017.10.016, indexed in Pubmed: 29191330.

8. Murdoch DR, Corey GR, Hoen B, et al. Clinical presentation, etiology, and outcome of infective endocarditis in the 21st century: the International Collaboration on Endocarditis-Prospective Cohort Study. Arch Intern Med. 2009; 169(5): 463-473, doi: 10.1001/archinternmed.2008.603, indexed in Pubmed: 19273776.

9. Fernández-Hidalgo N, Almirante B. Current status of infectious endocarditis: New populations at risk, new diagnostic and therapeutic challenges. Enferm Infecc Microbiol Clin. 2018; 36(2): 69-71, doi: 10.1016/j.eimc.2017.11.020, indexed in Pubmed: 29325999.

10. Habib G, Lancellotti P, Antunes M, et al. 2015 ESC Guidelines for the management of infective endocarditis. Eur Heart J. 2015; 36(44): 3075-3128, doi: 10.1093/eurhearti/ehv319.

11. Chu VH, Park LP, Athan E, et al. Association between surgical indications, operative risk, and clinical outcome in infective endocarditis: a prospective study from the International Collaboration on Endocarditis. Circulation. 2015; 131(2): 131-140, doi: 10.1161/ CIRCULATIONAHA.114.012461, indexed in Pubmed: 25480814.

12. Iung B, Doco-Lecompte T, Chocron S, et al. AEPEI Study Group. Cardiac surgery during the acute phase of infective endocarditis: discrepancies between European Society of Cardiology guidelines and practices. Eur Heart J. 2016; 37(10): 840-848, doi: 10.1093/eurheartj/ehv650, indexed in Pubmed: 26685134.

13. Habib G, Erba PA, Iung B. et el. Clinical presentation, aetiology and outcome of infective endocarditis. Results of the ESC-EORP EURO-ENDO (European infective endocarditis) registry: a prospective cohort study. Eur Heart J. 2019; 40(39): 3222-3232, doi: 10.1093/eurheartj/ehz620, indexed in Pubmed: 31504413.

14. Vallejo Camazón N, Cediel G, Núñez Aragón R, et al. Short- and long-term mortality in patients with left-sided infective endocarditis not undergoing surgery despite indication. Rev Esp Cardiol (Engl Ed). 2020; 73(9): 734-740, doi: 10.1016/j.rec.2019.09.011, indexed in Pubmed: 31767290.

15. Iversen K, Ihlemann N, Gill SU, et al. Partial oral versus intravenous antibiotic treatment of endocarditis. N Engl J Med. 2019; 380(5): 415-424, doi: 10.1056/NEJMoa1808312, indexed in Pubmed: 30152252.

16. Millar BC, Habib G, Moore JE. New diagnostic approaches in infective endocarditis. Heart. 2016; 102(10): 796-807, doi: 10.1136/heartjnl-2014-307021, indexed in Pubmed: 26908095.

17. Millar BC, de Camargo RA, Alavi A, et al. PET/Computed tomography evaluation of infection of the heart. PET Clin. 2019; 14(2): 251-269, doi: 10.1016/j.cpet.2018.12.006, indexed in Pubmed: 30826023.

18. Puerta-Alcalde P, Cuervo G, Simonetti AF, et al. PET/CT added to Duke criteria facilitates diagnosis and monitoring of long-term suppressive therapy of prosthetic endocarditis. Infect Dis (Lond). 2017; 49(9): 698-701, doi: 10.1080/23744235.2017.1300683, indexed in Pubmed: 28298163.

19. Núñez Aragón R, Pedro-Botet Montoya ML, Mateu Pruñonosa L, et al. Factores asociados y análisis descriptivo de la endocarditis infecciosa adquirida en el entorno hospitalario de un centro terciario de referencia. Enferm Infecc Microbiol Clin. 2013; 31(1): 15-22, doi: 10.1016/j.eimc.2012.03.014.

20. Charlson ME, Pompei P, Ales KL, et al. A new method of classifying prognostic comorbidity in longitudinal studies: development and validation. J Chronic Dis. 1987; 40(5): 373-383, doi: 10.1016/0021-9681(87)90171-8, indexed in Pubmed: 3558716.
21. Nashef S, Roques F, Michel P, et al. European system for cardiac operative risk evaluation (EuroSCORE). Eur J Cardio-Thoracic Surg. 1999; 16(1): 9-13, doi: 10.1016/s1010-7940(99)00134-7.

22. Nashef SAM, Roques F, Sharples LD, et al. EuroSCORE II. Eur J Cardiothorac Surg. 2012; 41(4): 734-44; discussion 744, doi: 10.1093/ejcts/ezs043, indexed in Pubmed: 22378855.

23. Baddour LM, Wilson WR, Bayer AS, et al. Infective endocarditis in adults: diagnosis, antimicrobial therapy, and management of complications: a scientific statement for healthcare professionals from the american heart association. Circulation. 2015; 132(15): 1435-1486, doi: 10.1161/CIR.0000000000000296, indexed in Pubmed: 26373316.

24. Prendergast BD, Tornos P. Surgery for infective endocarditis: who and when? Circulation. 2010; 121(9): 1141-1152, doi: 10.1161/ /CIRCULATIONAHA.108.773598, indexed in Pubmed: 20212293.

25. Fernández-Hidalgo N, Almirante B, Tornos P, et al. Immediate and long-term outcome of left-sided infective endocarditis. A 12-year prospective study from a contemporary cohort in a referral hospital. Clin Microbiol Infect. 2012; 18(12): E522-E530, doi: 10.1111/1469-0691.12033, indexed in Pubmed: 23077981.

26. Hidalgo-Tenorio C, Vinuesa D, Plata A, et al. DALBACEN cohort: dalbavancin as consolidation therapy in patients with endocarditis and/or bloodstream infection produced by grampositive cocci. Ann Clin Microbiol Antimicrob. 2019; 18(1): 30, doi: 10.1186/s12941-019-0329-6, indexed in Pubmed: 31629409.

27. Spaziante M, Franchi C, Taliani G, et al. Serum bactericidal activity levels monitor to guide intravenous dalbavancin chronic suppressive therapy of inoperable staphylococcal prosthetic valve endocarditis: a case report. Open Forum Infect Dis. 2019; 6(11): ofz427, doi: 10.1093/ofid/ofz427, indexed in Pubmed: 31737736.

28. Al-Omari A, Cameron DW, Lee C, et al. Oral antibiotic therapy for the treatment of infective endocarditis: a systematic review. BMC Infect Dis. 2014; 14: 140, doi: 10.1186/1471-2334-14-140, indexed in Pubmed: 24624933.

29. Mzabi A, Kernéis S, Richaud C, et al. Switch to oral antibiotics in the treatment of infective endocarditis is not associated with increased risk of mortality in non-severely ill patients. Clin Microbiol Infect. 2016; 22(7): 607-612, doi: 10.1016/j.cmi.2016.04.003, indexed in Pubmed: 27091094.

30. Heldman AW, Hartert TV, Ray SC, et al. Oral antibiotic treatment of right-sided staphylococcal endocarditis in injection drug users: prospective randomized comparison with parenteral therapy. Am J Med. 1996; 101(1): 68-76, doi: 10.1016/s0002-9343(96)00070-8, indexed in Pubmed: 8686718.

31. Stamboulian D, Bonvehi P, Arevalo C, et al. Antibiotic management of outpatients with endocarditis due to penicillin-susceptible streptococci. Rev Infect Dis. 1991; 13 Suppl 2: S160-S163, doi: 10.1093/clinids/13.supplement_2.s160, indexed in Pubmed: 2017645.

32. Tissot-Dupont H, Gouriet F, Oliver L, et al. High-dose trimethoprim-sulfamethoxazole and clindamycin for Staphylococcus aureus endocarditis. Int J Antimicrob Agents. 2019; 54(2): 143-148, doi: 10.1016/j.jijantimicag.2019.06.006, indexed in Pubmed: 31181351.

33. Cunha BA, Brahmbhatt K, Raza M. Haemophilus parainfluenzae aortic prosthetic valve endocarditis (PVE) successfully treated with oral levofloxacin. Heart Lung. 2015; 44(4): 317-320, doi: 10.1016/j.hrtlng.2015.04.006, indexed in Pubmed: 25998992.

34. Baddour LM. Long-term suppressive therapy for fungal endocarditis. Clin Infect Dis. 1996; 23(6): 1338-1340, doi: 10.1093/ clinids/23.6.1338-a, indexed in Pubmed: 8953098. 
35. Tan EM, DeSimone DC, Sohail MR, et al. Outcomes in patients with cardiovascular implantable electronic device infection managed with chronic antibiotic suppression. Clin Infect Dis. 2017; 64(11): 1516-1521, doi: 10.1093/cid/cix181, indexed in Pubmed: 28329125.

36. Baddour LM. Long-term suppressive antimicrobial therapy for intravascular device-related infections. Am J Med Sci. 2001; 322(4): 209-212, doi: 10.1097/00000441-200110000-00011, indexed in Pubmed: 11678518.

37. Lechner AM, Pretsch I, Hoppe U, et al. Successful long-term antibiotic suppressive therapy in a case of prosthetic valve endocarditis and a case of extensive aortic and subclavian graft infection. Infection. 2020; 48(1): 133-136, doi: 10.1007/s15010019-01321-6, indexed in Pubmed: 31123929.

38. Takano T, Terasaki T, Wada Y, et al. Treatment of prosthetic graft infection after thoracic aorta replacement. Ann Thorac Cardiovasc Surg. 2014; 20(4): 304-309, doi: 10.5761/atcs.oa.13-00059, indexed in Pubmed: 23801180.

39. Ramos-Martínez A, Blanco-Alonso S, Calderón-Parra J, et al. Endocarditis in patients with ascending aortic prosthetic graft: a series from a national referral hospital. J Am Coll Cardiol. 2020; 75(18): 2380-2382, doi: 10.1016/j.jacc.2020.03.035, indexed in Pubmed: 32381170 .

40. Swart LE, Gomes A, Scholtens AM, et al. Improving the diagnostic performance of f-fluorodeoxyglucose positron-emission tomography/computed tomography in prosthetic heart valve endocarditis. Circulation. 2018; 138(14): 1412-1427, doi: 10.1161/ CIRCULATIONAHA.118.035032, indexed in Pubmed: 30018167.

41. Pizzi M, Roque A, Fernández-Hidalgo N, et al. Improving the diagnosis of infective endocarditis in prosthetic valves and intracardiac devices with 18 f-fluordeoxyglucose positron emission tomography/computed tomography angiography. Circulation. 2015; 132(12): 1113-1126, doi: 10.1161/circulationaha.115.015316.
42. Heuzé C, Lepage L, Loubet $\mathrm{P}$, et al. Infective endocarditis after bentall surgery: usefulness of new imaging modalities and outcomes. JACC Cardiovasc Imaging. 2018; 11(10): 1535-1537, doi: 10.1016/j.jcmg.2017.12.007, indexed in Pubmed: 29454780.

43. Saitto G, Russo M, Pugliese M, et al. Infectious aortic root pseudoaneurysm after bentall procedure: to treat or not to treat by redo operation? Aorta (Stamford). 2019; 7(3): 90-92, doi: 10.1055/s-0039-1694013, indexed in Pubmed: 31614379.

44. Machelart I, Greib C, Wirth G, et al. Graft infection after a Bentall procedure: A case series and systematic review of the literature. Diagn Microbiol Infect Dis. 2017; 88(2): 158-162, doi: 10.1016/j.diagmicrobio.2017.03.002, indexed in Pubmed: 28330738.

45. Baddour LM, Cha YM, Wilson WR. Clinical practice. Infections of cardiovascular implantable electronic devices. N Engl J Med. 2012; 367(9): 842-849, doi: 10.1056/NEJMcp1107675, indexed in Pubmed: 22931318.

46. Botelho-Nevers E, Thuny F, Casalta JP, et al. Dramatic reduction in infective endocarditis-related mortality with a management-based approach. Arch Intern Med. 2009; 169(14): 1290-1298, doi: 10.1001/archinternmed.2009.192, indexed in Pubmed: 19636030.

47. Chirillo F, Scotton P, Rocco F, et al. Impact of a multidisciplinary management strategy on the outcome of patients with native valve infective endocarditis. Am J Cardiol. 2013; 112(8): 1171-1176, doi: 10.1016/j.amjcard.2013.05.060, indexed in Pubmed: 23831163.

48. Kaura A, Byrne J, Fife A, et al. Inception of the ,endocarditis team' is associated with improved survival in patients with infective endocarditis who are managed medically: findings from a before-and-after study. Open Heart. 2017; 4(2): e000699, doi: 10.1136/openhrt-2017-000699, indexed in Pubmed: 29344368. 